\title{
The Technology Realization of APP in University Libraries by the WeChat Official Account
}

\author{
Liu Xiaoyan, Zou Nu
}

Jiangxi Tellhow Animation Vocational College, Nanchang, Jiangxi, 330200

Keywords: WeChat official account, construction, colleges and universities, library, APP, technology application

\begin{abstract}
In the informatization age, more and more industries have realized the significance of introducing information technological means and made it as an important driver. Similarly, in the development of colleges and universities, only by applying information technology means can the development of them be injected into impetus so as to meet the needs of students, keep pace with the tendency in the era. Give the current development, WeChat Official Account can be used as a platform for information disclosure in an all-round way for students and teachers inside the colleges and universities. Specifically, in the growth of libraries in the colleges and universities, the construction of APP of libraries can take the advantages of technological application and bring more convenience for readers. Based on this, the author suggested that, the development of WeChat service program can be used to develop and integrate internal business system of library and its resources within the internal management framework of OneThink. It will manifest four function modules comprehensively by applying service program or other programs by sending information automatically to communicate with managers in the library instantly. The main goal of the backstage module of the system is to realize system configuration, plug-in management, and user management, greatly improving the service quality of the library by means of WeChat official account.
\end{abstract}

As is known to all, WeChat official account is a platform for information acquisition, data sharing and content delivery developed by the Tencent. Any individual or institute can register an exclusive official account in the WeChat, by which they can send all information including speech, image-text, text and video timely to their users. The fundamental function comprises: keyword reply, reply for being added, group text messaging, developer mode and customized menus. The development mode of WeChat official account can offer various routine interfaces for developers who call these interfaces considering the real requirements of business integration, develop service programs on the WeChat and ultimately, providing more diversified services.

\section{The application of WeChat official account in the library's APP in colleges and universities}

APP, short for mobile application program, refers to application programs by virtue of mobile devices like smartphone. In the development of APP of libraries in the colleges and universities, the mobile application programs should be paid much attention to provide a variety of services: mobile identity authentication, mobile reading, mobile paying and mobile search. Furthermore, it has the function of online reading, online research and online resource sharing, which enhances the openness and feasibility of library operation, promotes the construction of autonomous knowledge acquisition and virtual studying system, being of huge practical significance for the library development. Since the WeChat has relatively comprehensive functions with many users, it can realize point-to-point information push services. Thus, the building of library APP by the WeChat is an inevitable tendency for the colleges and universities in the near future for its less financial investment, simple and convenient construction, rich and flexible functions and the realization of cross-platform application.

Currently, more and more technicians in China have noticed the significance of construction methods of WeChat in developing the library APP in the colleges and universities. Therefore, they 
study the library services in an all-round way, take service platform of the WeChat official account as a basic way to meet the development needs of library and work out practical design and ideas. On the basis, technological means like simulation of HTTP request or data feature analysis can be utilized to study information receiving, system command word, service information, response message and information data to demonstrate the function and applied value of the WeChat official account.

Through the analysis and discussion, the author learned that the application of WeChat official account in the library APP in the colleges and universities is necessary, which bridges the distance between readers and mangers with high practical significance and operability. Many libraries have utilized this technological means to clarify the design function, service situation, design concept and operation strategy of WeChat, make comprehensive analysis and research, meanwhile, they propose targeted suggestions for building library APP by WeChat, which promotes the educational level as well as the development of colleges and universities,

\section{The construction of library APP by the WeChat official account}

The mobile library services in most public libraries of the United States offer position, contact, and operation time and other data for readers, at the same time, they provide practical services including many people-oriented services in renting, health care and medical treatment considering the reading habits of readers. While libraries in colleges and universities have learned from public libraries, add many modules like study room, docking of home page in colleges and universities, information search of students and teachers, which makes the application function of APP system diversified and comprehensive. And the system can integrate and gather all resources of library to make its service more systematic, offer targeted guidance for users and enhance the service quality [1].

\subsection{Resource retrieval module}

The system, by utilizing service program of WeChat, integrates and gathers data and information, guides users to determine the specific position and related information about database, electronic journal, and electronic library by the information retrieval in the WeChat, showing the strengths of automatic management system of libraries. On the module, users can lend popular books, directly search the notice of library news, popular books or journals, use targeted navigation services, demonstrating the real value of the library's APP. [2-4]

\subsection{Service module}

The service module can manifest all data related to library as well as users, covering user views, online consultation, or message history, and users select related topics to enter this module.

For example, users can send specific information to the office software of libraries combing their search requirements. After managers of libraries log in their accounts, they can see directly the related suggestions, reply and deal with user requirements, offer related retrieval links to meet the reading needs of readers. As for the users, when consulting, they can input information in the WeChat, and send it to the mangers. By means of transmissibility of the client side, several mangers can read the message simultaneously, and provide services in real time. [5-7]

\subsection{Personal library module}

After subscribing the WeChat platform of libraries, users can bind their library cards directly and search for the lending information, finish renewal and the second reservation of books. In addition, other functions can also be set like book recommendation, library preview, which can be seen in the module of "Subscription", covering all consultation information like journal, science and technology, humanity, video, newspaper, education or sports.

\subsection{Instant information exchange module}

The reply and disposure of user questions and requests are achieved by building knowledge base, 
developing robot service programs or automatic information sending programs. What is more, data information about library cards of users can be used to push information, such as book reservation, asking for overdue books, resource dynamics automatically. If users have subscribed the WeChat official account of the library, then, the system shall retrieve the surname or gender of users and send personalized welcoming messages. [6-10]

\section{The realization of construction and development of library APP on the WeChat official account}

The service program of WeChat refers to the application of the latest version of ThinkPHP3.2 under the management framework of OneThink to release open source license of Apache2, rename the space mechanism in the new design method by combining theories of plug-in, modularization, and theorization so as to achieve the efficient expansion of hook mechanism and plug-in by utilizing service program of WeChat under the OneThink management framework. The plug-in here means the independent modules applied in the system function, and the main function of hook is to determine the real position of plug-in and show its function. [11] Then, the scalability of plug-in can be used to make its applications more flexible and convenient. Therefore, it is suggested that, each function module of APP of the library is designed as a unique plug-in. Particularly in a plug-in management interface of the backstage, by closing or opening plug-in, all functions of data management expansion can be realized, reducing the impact of existing data as much as possible.

The goal of the front module of WeChat service program is mainly to demonstrate the functions of APP, while the backstage is to show the functions of user management, plug-in management and system settings.

\subsection{The process of implementation of the APP of library}

First of all, readers use all means in the APP of the library to send various parameters to the interface of the WeChat service program including information reply, cancellation of public account, and menu clicking.

Secondly, the interface program, after receiving the data in the form of xml by the WeChat official account, will decompose the data, which will be transmitted into the function module. By means of the front module, the interface of service program in the WeChat can realize the efficient connection.

Thirdly, after making judgement on the type of data, the interface program will transmit related data to different plug-in and process further. When receiving related data, the service program will search and determine the position of key words and find corresponding ID of business data. Given the difference of name of plug-in, related plug-in is loaded, and then, transmits received information to the related plug-in. After the processing of plug-in, result data will be returned to the service program, and data information will be encapsulated and transformed in the appropriate form by the service program of the WeChat, which will be returned to the APP of the library. Since returned data information includes link address, readers can enter the micro-website via the linkage to finish needed business operation. [12-14]

Fourth, if the type of received information by the interface program is E-vent, then it can be confirmed as the event type. Combining the real type of the event, it will be processed into the plug-in and skip to other websites.

\subsection{The function realization of APP of library}

Firstly, personalized message alert. The function of automatic alert for each lending information is the crucial function of APP in the library, increasing convenience and practicality of the APP, as well as the dependence of users for the APP by obtaining more data and meeting more requirements of function application.

Secondly, robot response. As one of the interesting functions of library's APP, robot response can complete semantic analysis, respond automatically according to specific language meaning, provide functions of weather forecast, translation, and self-learning, which will bring better user experience, 
raise their recognition and support for the platform, and increase their reliance on this APP.

The robot auto-answer plug-in can provide data processing support for the applications of robot by using DeepQA technology. After receiving related data, the interface of service program of the WeChat will make its judgement on the type of information. If the data are not the key words of the plug-in, the interface program will process related data automatically and then send it to the AOI interface of the Turing robot, which will determine the returning format as the JSON result data.

\section{Conclusion}

In a word, with the rapid development of information technology, the implementation of library management in colleges and universities requires strong support of information technology. And applying service platform of WeChat official account to build APP system for libraries in the colleges and universities will bring more convenience for readers, bridge the gap between library managers and readers. The construction of this platform will enhance the management efficiency of libraries in colleges and universities, offer quality services, make library management more modern, intelligent, and informative, and keep pace with the tendency in the new era.

\section{Acknowledgements}

Fund Item: The thesis is supported by Humanity and Social Science Project of Jiangxi Province, named the Research and Application of Mobile Services of APP in University Library Based on Knowledge Utilization Habit of Students (Project Number: TQ17024).

\section{References}

[1] Zhang Changheng, Huang Fang. Using WeChat public platform to construct the technical implementation of university library APP [J]. Book intelligence work,2015,15(4):37-43.

[2] Han Meng, Li Juan, Xi Yaping, et al. The university library USES WeChat public platform to think about information service [J]. Library journal,2014,26(10):111-115.

[3] Bai Mingfeng, Kuang Huihua. Application of light application model in mobile information service of university library and its reference -- based on the analysis of WeChat public number of university library [J]. Intelligence data work,2014,26(4):78-81.

[4] Xie Yuhua. Development and application of WeChat public platform of university library in sichuan province [J]. Neijiang technology, 2013,38(9):60-61.

[5] Bao Jing. Application and research of WeChat public platform based on digital library mobile information service [J]. Journal of tonghua normal university,2016,37(6):132-135.

[6] Wang Xiaolei. Comparative study of mobile library terminals in "211" universities in shaanxi province [J]. Journal of agricultural book intelligence, 2011,29(8):105-108.

[7] He Yun. Exploration on the construction of mobile library of multi-platform collaborative universities [J]. Electronic production, 2011,11(3):35-36.

[8] Hao Weifu. A brief analysis on the development of WeChat public platform in university libraries [J]. Science and technology horizon,2016,22(27): 383, 231.

[9] Chen Jinghui, Liu Jiajia, Wang Yingjuan et al. Digital library construction based on Internet communication technology [J]. Digital technology and application,2016,29(3):235-235.

[10] Wang Lanwei. A pair of multi-reading promotion exploration in mobile clients $*_{--}$taking WeChat public platform as an example [J]. Library research,2016,46(3):63-67.

[11] Bian Qian. Based on the development model, the design of WeChat public platform service [J]. China management informatization,2015,26(18):186-186. 
[12] Wang Yufan. On the construction of the communication force of academic journals under the new media environment -- a case study of WeChat public platform [J]. Journal of news research,2016,7(14):350-350.

[13] Wang Bo. Application of WeChat public platform in domestic library service [J]. Modern communication,2016,14(2):121-122.

[14] Wang Xia. Construction of digital library service model based on mobile Internet [J]. Journal of Jishou university (natural science edition),2014,35(4):89-92. 